\title{
LA DEVOCIÓN EN LA CASA: CÓRDOBA EN EL ANTIGUO RÉGIMEN
}

\author{
POR \\ ANTONIA GaRRIDo Flores \\ Doctoranda de la Universidad de Córdoba
}

\begin{abstract}
RESUMEN
La religión era una parcela fundamental de la vida del Antiguo Régimen, un elemento que de manera transversal invadía todos los ámbitos de la vida de la Edad Moderna, por verdadera fe o por apariencia social. Consecuentemente fue muy frecuente que entre los objetos que componían el ajuar femenino se encontraran un número considerable de objetos destinados a la devoción doméstica o al culto privado que generalmente serían exhibidos en el espacio privado doméstico o en público en manifestaciones de carácter religioso. Con este trabajo se pretende dar una primera visión de todo lo concerniente a dichos objetos de culto, tanto los que eran de uso personal y privado como los que se instalaban en los nuevos hogares.
\end{abstract}

PALABRAS ClAVES: Devoción, mujer, ajuar, casa, espacio privado, vida cotidiana, Edad Moderna.

\section{THE DEVOTION IN THE HOUSE: CORDOVA IN THE FORMER REGIMEN}

\begin{abstract}
Religion was an essential part in the life of the Old Regimen, an element which in a transversal manner did invade the scope of life in the Modern Period; so it is not unusual to find that among the objects composing the trousseau the majority of them were items dealing with devotion and religious worship, articles which were generally exhibited in the domestic private sphere as well as in public manifestations of religious nature. On this work the first vision is tried to meet to everything relating to the above mentioned objects of worship so much those who were of personal and private use and those who were establishing themselves in the new homes.
\end{abstract}


KEY WORDS: Devotion, woman, home, trousseau, private sphere, life, Modern Period.

$\begin{array}{ll}\text { Recibido/Received } & 26-01-2013 \\ \text { Aceptado/Accepted } & 31-01-2014\end{array}$

Este trabajo forma parte de una línea de investigación propia dedicada al estudio del universo de la casa en la Córdoba de los siglos XVII y XVIII, simbolizados en 1700 y 1800, los dos años analizados, abarcando desde aspectos físicos de su estructura, su distribución espacial y funcional, pasando por los objetos que la visten, llegando hasta los seres que la habitan y que conforman las estructuras familiares. Una temática más de lo que historiográficamene se denomina «vida cotidiana», «vida privada», 0 «cultura material», esta investigación doctoral se suma, pues, así a las varias y muy interesantes aportaciones que aquella parcela está recibiendo en los últimos años, como son las de Bibiloni Amengual, Bolufer Peruga, Muñoz Navarro, Bartolomé Bartolomé, Franco Rubio, García Fernández, Peña Díaz entre otras o las clásicas de Raffaela Sarti, Pouns o Thompson.

Del universo doméstico esta contribución pretende ofrecer un panorama de la religiosidad privada dentro del espacio familiar a través de los objetos de culto doméstico que la mujer lleva en su dote, bien por ser de nueva adquisición, bien por ser heredados o regalados, su posible evolución en el tiempo estudiado, y el posible significado taumatúrgico que desprendían todos estos artículos. ${ }^{1}$ Recordemos que no en vano la mujer era la principal portadora de los diferentes elementos que conformarían la estética y el uso funcional de cada uno de los espacios de la futura vivienda, y téngase en cuenta que se manejan espacios, no habitaciones, porque en esta época las moradas se componían generalmente de una sola estancia donde se distribuían los artículos que, por su uso o aplicación, eran los que realmente conformaban los diferentes lugares en que se distribuía un hogar. De todos ellos este artículo analiza las piezas de carácter religioso que la mujer portaba en su ajuar. Metodológicamente, lo hemos dividido en dos apartados para una mejor compresión y organización del discurso. En el primero analizaremos la cotidianidad de los objetos religiosos que la mujer aportaba al nuevo hogar desde las distintas variables posibles, es decir, cuántos eran, cuáles eran y a qué advocaciones religiosas estaban dedicadas, con qué materiales estaban confeccionados, cómo evolucionan y quiénes poseían este patrimonio religioso. En el segundo apartado estudiaremos los casos más notables, las

\footnotetext{
${ }^{1}$ Se han consultado 103 cartas de dote y arras de los 11 escribanos que más cartas de dote y arras escrituraban y desarrollaban su oficio en la ciudad de Córdoba en 1700 y 1800 . De ellas se han contabilizado, clasificado y estudiado 496 objetos religiosos distintos recogidos en estos documentos.
} 
singularidades que rompen la norma, los que se salen de la generalidad, bien por la cantidad, por la calidad de los objetos que presentan y por la personalidad de la mujer dueña de la dote.

\section{LA REGULARIDAD EN LA POSESIÓN DE LOS OBJETOS RELIGIOSOS}

Según acabamos de exponer, centra nuestra atención en este apartado el análisis pormenorizado de los objetos religiosos domésticos para todos los documentos notariales al efecto examinados y desde los diversos ítems antes indicados.

\section{¿Cuántos eran los objetos religiosos del culto privado?}

$\mathrm{Al}$ presentar este trabajo hemos apuntado que era muy frecuente que las mujeres en su ajuar dispusieran de objetos de culto; esta afirmación se sustenta en la comprobación de que estos objetos aparecen en tres de cada cuatro relaciones de bienes femeninos consultadas, siendo esta proporción incluso mayor en 1700 que en 1800 .

Las mujeres solían disponer de entre uno y tres objetos destinados al culto entre sus bienes, si bien hay que precisar que igualmente encontramos casos en las que las propietarias podían llegar a tener más de treinta de estos objetos e incluso alguna supera muy ampliamente aquella cifra, casi cinco veces, como doña Francisca Herrera Luque, que dispuso de ciento cuarenta y seis objetos religiosos en 1800, y que por ello, por su excepcionalidad y singularidad, nos ocuparemos de su caso en el segundo apartado de esta aportación. ${ }^{2}$

Hemos comprobado que el valor medio de estos objetos se sitúa en torno a los cuarenta reales de vellón, y que más del $60 \%$ de los objetos de culto tenían un precio inferior a este valor medio. El amplio abanico de precios que hemos encontrado abarca desde los tres reales de vellón del modesto lienzo de san Francisco de Paula propiedad de la viuda doña Francisca Gallego de Córdoba hasta los mil setecientos ochenta y tres reales de vellón del rosario de granates que poseía doña Antonia Luque y Leiva.

Por otra parte, y en relación al porcentaje que estos productos representaban respecto del valor total de los bienes incluidos en las dotes analizadas se puede considerar pequeño, ya que se ha observado que en el siglo XVII era de un

${ }^{2}$ Archivo Histórico Provincial de Córdoba (en lo sucesivo, AHPCO.P.N), Protocolos Notariales 31, Sig. 2.185p, (1800), sf. 
$3,66 \%$ y en el siglo XVIII era tan solo de $1,87 \%$.Este porcentaje nos puede parecer pequeño pero, si lo comparamos con el valor de otros bienes que la mujer lleva en su ajuar, comprobamos que es muy similar al gasto que aquélla hace en objetos destinados a calentar o iluminar el hogar, braseros, bujías y candiles principalmente. Prueba de lo que indicamos es la siguiente tabla que relaciona los artículos de devoción registrados en los listados de bienes de los años 1700 y 1800 con sus correspondientes cantidades.

Tabla I:

Artículos de devoción en los siglos XVII y xVIII:

\begin{tabular}{|l|c|c|c|c|c|c|}
\hline Años & \multicolumn{2}{c}{$\mathbf{1 7 0 0}$} & \multicolumn{2}{c|}{$\mathbf{1 8 0 0}$} & \multicolumn{2}{c|}{ TOTAL Años } \\
\hline Articulos & Cantidad & \% & Cantidad & \% & Cantidad & \% \\
\hline Cruces & 7 & 2,66 & 143 & 61,4 & 150 & 30,24 \\
\hline Rosarios & 60 & 22,81 & 65 & 27,9 & 125 & 25,20 \\
\hline Lienzos & 122 & 46,39 & - & - & 122 & 24,60 \\
\hline Agnus & 31 & 11,79 & 8 & 3,43 & 39 & 7,86 \\
\hline Imagenes & 33 & 12,55 & 3 & 1,29 & 36 & 7,26 \\
\hline Relicarios & 6 & 2,28 & 3 & 1,29 & 9 & 1,81 \\
\hline Láminas & - & - & 9 & 3,86 & 9 & 1,81 \\
\hline Crucifijos & 2 & 0,76 & - & - & 2 & 0,40 \\
\hline Pila de agua bendita & 1 & 0,38 & - & - & 1 & 0,20 \\
\hline Retablo & 1 & 0,38 & - & - & 1 & 0,20 \\
\hline Cuadro & - & - & 1 & 0,43 & 1 & 0,20 \\
\hline Salterio & - & - & 1 & 0,43 & 1 & 0,20 \\
\hline Total & 263 & 100 & 233 & 100 & 496 & 100 \\
\hline
\end{tabular}

Fuente: Elaboración Propia

Según los datos obtenidos a partir de la cata de documentos realizada, se puede apreciar que la tendencia en el periodo estudiado es de una disminución notable de los objetos de culto. Se comprueba que en términos generales los objetos que se instalaban en el hogar destinados a la devoción doméstica y los que se utilizaban para el culto personal disminuyen en el tiempo analizado. Así mismo se ha verificado que los artículos que son para el rezo colectivo como eran los lienzos de advocaciones religiosas o las imágenes de bulto, es un ejemplo la imagen de la Virgen con el Niño sin corona que aporta al nuevo hogar 
la viuda doña Josefa Buenaño Carrasquilla, ${ }^{3}$ son muy numerosas en las casas del siglo XVII desapareciendo o con presencia testimonial en el siglo XVIII. Los lienzos y las imágenes para colocar en la casa eran muy importantes no solo por su número sino por el significado que tenían para los que habitaban la casa y los que la visitaban. Los lienzos y las imágenes tienen el valor de la devoción y el de la instrucción en la fe, también cuentan con valor ornamental para el espacio habitado. Es interesante analizar, según la tabla anterior, que en el siglo XVII no aparecen láminas al tiempo que se documentan una gran cantidad de lienzos, ciento veintidós. Por el contrario en el siglo XVIII no aparecen lienzos y sí las láminas. Esto podría suponer el cambio de gustos de un objeto sobre otro porque por la cuestión económica creemos que no debe ser porque analizando los precios de los artículos de 1700 y los de 1800 encontramos que en numerosos casos los lienzos son de una cuantía económica menor.

Algo similar ocurre con los objetos para el rezo y la devoción personal que disminuyen su número, como en el caso de los agnusdéis o de los relicarios, aunque determinados objetos como el rosario aumenten sus unidades ligeramente.

Es necesario comentar y justificar el aumento de cruces que se observa en la tabla. El aumento de cruces que se produce en 1800 está motivado por dos causas: la primera es que la dote de una de las mujeres estudiadas, doña Francisca de Herrera y Luque, ${ }^{4}$ este año contiene la mayoría de estas piezas religiosas, 134, lo que distorsiona gravemente el resultado numérico, y la segunda es que en los documentos analizados no se diferencia de manera clara entre cruces que la mujer puede llevar alrededor del cuello o engarzada en un rosario y las que se situaban en algún lugar de la casa como podía ser la pared o sobre cualquier mueble. Creemos que la mayoría de estos objetos eran para el primer uso que hemos comentado porque en otros casos, como muestra la tabla, se han contabilizado crucifijos que suponemos que eran elementos destinados a colocarse en algún rincón de la vivienda. El análisis pormenorizado de la evolución de estos objetos se realiza más adelante en un apartado específico. Por lo tanto en términos generales se comprueba que el sentimiento de religiosidad era muy fuerte en todo el tiempo estudiado y que existe una religiosidad popular que se manifiesta en muchos aspectos de la vida cotidiana de los habitantes de aquellas casas.

\section{¿Cuáles eran los objetos religiosos?}

Para el estudio general de los objetos religiosos diferenciaremos entre los artículos destinados al uso personal de los que serían exhibidos en el hogar.

\footnotetext{
${ }^{3}$ AHPCO.P.N., 30,Sig, 10.583p,(1700), f.30r:

${ }^{4}$ AHPCO.P.N., 34,Sig, 2.185p,(1800), sf.r:
} 
Entre los de uso personal que aparecen documentados están: rosarios, agnusdéi ${ }^{5}$ cruces, relicarios y salterios.

Relativo a los agnusdéis debemos señalar que estos objetos eran medallas generalmente de cera y/o plata u oro en cuyas caras llevaba un cordero con la inscripción AGNUSDEI y por la otra cara la imagen de Cristo, la Virgen o un santo determinado. ${ }^{6}$ Recordemos que la cera del agnusdei tiene su origen del cirio pascual, mezclada con los santos óleos y agua bendita, que los Papas emitieron en Roma desde la Antigüedad hasta prácticamente el siglo xx. Vaciados desde el siglo XVII en moldes de dos caras - anteriormente sólo en una-, en su anverso figura siempre un relieve del Cordero de Dios, bien recostado, bien de pie, con cruz y estardarte sobre el libro de los Siete Sellos. Rodea siempre la imagen una inscripción que reza: Ecce Agnus Dei qui tolli pecata mundi, así como el nombre del Papa que lo consagró, acompañado del año en que se hizo, la cronología de su pontificado y su emblema heráldico. Su condición de objeto consagrado hizo que los Agnusdeis fueran piezas muy preciadas y codiciadas entre los fieles cristianos dado su carácter protector frente a males que pudieran afectar al alma, al cuerpo o a sus casas. E incluso su valor fue tal que se llegó a su falsificación y comercio ilícito, como lo atestiguan las disposiciones de excomunión promulgadas por varios pontífices. En la época estos objetos eran muy valorados por el origen pontifical que atesoraba junto al valor religioso y de protección que pudiera tener para su portador. ${ }^{7}$

Por otra parte, y según arroja la cuantificación, los rosarios junto a los agnusdéis son los artículos más numerosos. Posiblemente el motivo de que los rosarios fueran tan numerosos fue la gran difusión que los dominicos hicieron de este objeto religioso para la correcta realización de los rezos diarios por los fieles. ${ }^{8}$ De igual forma se puede apuntar que estos objetos, como los agnusdeis o las cruces, además de constituir un elemento ornamental para la mujer que los disfrutaba en ocasiones se les otorgaban el valor de talismán. ${ }^{9}$

Finalmente debemos tener en cuenta que el rosario es de los pocos elementos que acompaña a la persona en vida y que acompañaba al agonizante

\footnotetext{
${ }^{5}$ RAE: Agnusdéi. 3. $m$. Relicario que especialmente las mujeres llevaban al cuello.

${ }^{6}$ Instituto de la Lengua Gallega. http://sli.uvigo.es. [4/7/2013].

${ }^{7}$ http://www.identificacion-numismatica.com.[6/2/2013].

${ }^{8}$ Valero Moreno, M. 2003 «Religiosidad popular en Córdoba en el siglo XVII, cofradías del Santo Rosario» en C. Álvarez Santaló, Ma J. Buxó Rey, S. Rodríguez Becerra (Coords.), La religiosidad popular. Hermandades, romerías y santuarios, V.III:485-506. Barcelona:Anthropos Editorial.

${ }^{9}$ González Sánchez, C.A. 2012 «Imagen de culto y espiritualidad. Funciones y normas de uso en la vida cotidiana (siglos XVI-XVII) en M. Peña Díaz (Ed.), La vida cotidiana en el mundo hispánico (siglos XVI-XVII), 387-405. Madrid: Abada Editores.
}

Hispania Sacra, LXVI

134, julio-diciembre 2014, 575-600, ISSN: 0018-215X, doi: 10.3989/hs.2014.062 
sirviéndole como ayuda para el tránsito hacia la muerte..$^{10}$ Como hemos señalado, estos objetos servían al individuo para su religiosidad personal y propia, donde su devoción particular a una determinada advocación religiosa le acercaba más a Dios.

Pero junto a los objetos de uso personal aparecen objetos de culto religioso que están destinados al espacio doméstico. No se puede saber a ciencia cierta si estos elementos eran meramente decoración, o si eran, por el contrario, recursos pedagógicos para todos aquellos que los contemplaran, o bien piezas casi mágicas a las que se les pedían protección y gracias, y que por este motivo se colocaban en la casa. ${ }^{11}$ Creemos que estos artículos se disponían para ser exhibidos bien por verdadera devoción de los dueños de la casa a la imagen, bien para poner de manifiesto a los visitantes la religiosidad de la familia que habitaba la casa, o simplemente cumpliendo una función estética de embellecimiento. Por otra parte, debemos considerar que portar algún objeto de culto o disponerlo en la casa puede acercarnos a la idea de fervor religioso, pero igualmente nos acerca a la noción más pagana y supersticiosa del individuo que utiliza estos objetos como medio para obtener favores y protección. ${ }^{12}$ No podemos olvidar la labor pedagógica que mostraban las imágenes para enseñar las sagradas escrituras y como estas figuras acercaban lo divino al hombre. Las representaciones más intimidatorias y dolorosas de la pasión de Cristo instruían a la población para que se alejara de los bienes mundanos siguiendo las reglas establecidas y para que encaminara su comportamiento a una muerte en santidad..$^{13}$

Entre estos artículos encontramos principalmente imágenes de bulto del Niño Jesús, alguna imagen mariana, y lienzos. Lienzos de los cuales no se nos aporta información sobre su técnica pictórica aunque sí, en numerosos casos, de su advocación religiosa.

En 1800 se ha constatado que cinco láminas de las nueve contabilizadas iban enmarcadas con marcos negros o dorados. Además de los anteriores objetos encontramos algunos crucifijos, retablos, cuadros e incluso una pila de agua bendita.

${ }^{10}$ Gómez Navarro, S. 1998-1999. «Acercamiento a la muerte desde la antesala de la muerte misma: las ultimidades», Revista de historia moderna: Anales de la Universidad de Alicante 17:21-32.

${ }^{11}$ González Sánchez, C.A. 2012 «Imagen de culto y espiritualidad. Funciones y normas de uso en la vida cotidiana (siglos XVI-XVII)» en M. Peña Díaz (Ed.), La vida cotidiana en el mundo hispánico (siglos XVI-XVII), 387-405. Madrid: Abada Editores.

${ }^{12}$ Zamora Acosta, E. 2003. «Aproximación a la religiosidad popular en el mundo urbano: el culto a los santos en la ciudad de Sevilla» en C. Álvarez Santaló, Ma J. Buxó Rey, S. Rodríguez Becerra (Coords.), La religiosidad popular. Antropología e Historia, V.I: 527-562. Barcelona: Anthropos Editorial.

${ }^{13}$ González Sánchez, C.A. 2012 «Imagen de culto y espiritualidad. Funciones y normas de uso en la vida cotidiana (siglos XVI-XVII) en M. Peña Díaz (Ed.), La vida cotidiana en el mundo hispánico (siglos XVI-XVII), 387-405. Madrid: Abada Editores. 


\section{¿De qué advocaciones religiosas?}

Según apunta Zamora Acosta en su trabajo sobre la religiosidad urbana el habitante de la ciudad necesita un culto cercano que le dé una cierta seguridad en el caos que representa la urbe. ${ }^{14}$ Por ello se acoge a las imágenes de diferentes advocaciones de santos, vírgenes y cristos. En el espacio temporal estudiado observamos que imágenes de temática cristológica y mariana son las más abundantes y entre ellas las más populares son las representaciones de Jesucristo en la Cruz, las del Nazareno y las del Niño Jesús. Es reseñable que muchas de estas imágenes de Jesucristo y del Niño Jesús llevaban un dosel de tela y en los casos que vienen recogido apreciamos que el tejido era de damasco. Este dato nos podría indicar una vuelta a un cierto teocentrismo. Así mismo y junto a los anteriores encontramos lienzos y cuadros de diferentes vírgenes como Nuestra Señora de la Soledad, la Virgen del Carmen, Nuestra Señora de las Angustias y numerosas imágenes de la Purísima. Recordemos el gran fervor mariano que existía en la Córdoba de la época y del que dejó constancia María José Escribano Nieto en su trabajo presentado en el XX Simposium sobre advocaciones marianas celebrado en el 2012 en el Escorial. ${ }^{15}$

Muy abundante es la lista de imágenes de santos y santas que aparecen entre las que se aprecian las de santa Verónica, la Magdalena, santa Catalina y santos como san Francisco de Paula y de Asís, san Gerónimo, san Sebastián o san Juan entre otros. No hemos constatado que las advocaciones religiosas tuvieran alguna relación con los nombres de pila de las portadoras ni con las cofradías existentes en sus barrios de origen. Todas estas imágenes eran testigos e intermediarios de las plegarias y de las peticiones de los hombres ante Dios. ${ }^{16}$

Entre las más interesantes advocaciones encontramos las del Cristo de la Cabrilla y la de la Virgen del Pópulo que no pertenecen a la zona urbana de Córdoba. El Cristo de Burgos o de la Cabrilla tiene su origen, como su nombre indica, en esta ciudad castellana. Se cree que esta devoción se extiende por toda Andalucía afianzándose en el siglo XVII a causa del deseo de auxilio provocado

\footnotetext{
${ }^{14}$ Zamora Acosta, E. 2003. «Aproximación a la religiosidad popular en el mundo urbano: el culto a los santos en la ciudad de Sevilla» en C. Álvarez Santaló, M ${ }^{\mathrm{a}}$ J. Buxó Rey, S. Rodríguez Becerra (Coords.), La religiosidad popular. Antropología e Historia, V.I: 541. Barcelona: Anthropos Editorial.

${ }^{15}$ Escribano Nieto, $\mathrm{M}^{\mathrm{a}}$ J. 2012 «La religiosidad popular cordobesa: las advocaciones de gloria. Pervivencia y desaparición de estas imágenes y sus lugares de culto» en Advocaciones marianas de gloria, XX Simposium del Instituto Escurialense de Investigaciones Históricas y Artísticas, San Lorenzo del Escorial: 263-314.

${ }^{16}$ Gómez Navarro, S. 2008. «Un momento ideal para acordarse de los Santos: Cuando la muerte llega: la cláusula testamentaria de la intercesión en la España Moderna» en Culto a los santos: cofradías, devoción, fiestas y arte. Ediciones Escurialenses : Real Centro Universitario Escorial-María Cristina:57-74.
}

Hispania Sacra, LXVI

134, julio-diciembre 2014, 575-600, ISSN: 0018-215X, doi: 10.3989/hs.2014.062 
por las múltiples epidemias de peste y hambrunas que se dan en esta época. ${ }^{17}$ Por su parte la Virgen del Pópulo tiene su origen en la ciudad de Cádiz. La imagen se encontraba, y encuentra en la actualidad, sobre el arco que da entrada al barrio medieval del mismo nombre. Según cuenta la leyenda el lienzo salió indemne tras el saqueo que sufrió la ciudad en 1596 por parte de las tropas inglesas. Curiosamente estos dos lienzos los lleva la misma mujer, doña Antonia Luque Leiva. Esta joven soltera lleva veintisiete lienzos más de diferentes santos, cristos y vírgenes entre sus bienes dotales. Esta cantidad de lienzos nos indica que esta mujer decoraba por completo su casa con cuadros de temática religiosa.

\section{¿Con qué materiales están elaborados los objetos religiosos?}

Con referencia a los materiales empleados en la fabricación de los objetos la plata es con diferencia el más empleado en la producción de los objetos religiosos. Así comprobamos que los objetos son elaborados en su totalidad con este metal o que se utiliza para la realización de los elementos de engarce en otras piezas. Entre los elementos construidos, totalmente o en parte, con plata para uso personal que se han documentado en este trabajo encontramos rosarios, agnusdeis y cruces. Señalaremos que era frecuente en las hechuras de los rosarios la utilización de la plata para montar los engarces de las cuentas, las cuales podían ser del mismo material o estar realizadas con otro diferente. Entre éstos encontramos la exótica madera de cachimbo ${ }^{18} \mathrm{el}$ cuarzo denominado venturina, las cuentecillas de la India denominadas frutilla ${ }^{19} \mathrm{o}$ las cuentas de coral que llevaba la rica dote de doña Josefa Buenaño Carrasquilla. ${ }^{20}$ Si hablamos de materiales especiales, curiosamente encontramos una cruz de ébano embutida en marfil tasada en tan solo cuatro reales que era igualmente de esta mujer.

En relación a los objetos para el culto doméstico encontramos una pequeña pila de agua bendita totalmente de plata con su cruz y un remate valorada en cincuenta y ocho reales de vellón. Esta pila aparece entre los bienes de doña Antonia Rafaela del Rosal en su cuantiosa dote de cincuenta y siete mil doscientos reales de vellón. ${ }^{21}$ De esta mujer trataremos más ampliamente en el apartado destinado a las singularidades. Así mismo entre los objetos para el culto doméstico encontramos abundantes láminas. No se ha constatado si estaban o no fabricadas con madera, metal u otro material de soporte, si eran estampaciones o se

\footnotetext{
${ }^{17}$ Gila Medina. 2011. «El Cristo de Burgos o de Cabrilla en la Diócesis de Granada», Contraluz: Revista de la Asociación Cultural Arturo Cerdá y Rico 8: 129-164.

${ }^{18}$ AHPCO.P.N., 30,Sig. 10.583p, (1700), f.30r

${ }^{19}$ RAE: Frutilla.1. f. Cuentecilla de las Indias para hacer rosarios.

${ }^{20}$ AHPCO.P.N., 30,Sig, 10.583p,(1700), f.30r:

${ }^{21}$ AHPCO. P.N., f.897r
} 
trataba de pinturas. Lo que sí sabemos es que el arte de tallar en madera o la xilografía era una técnica muy utilizada en la época debido a su bajo precio frente a la realización de cuadros en metal que era muy costosa y poco utilizada. ${ }^{22}$ Las imágenes de bulto solían ser de madera y en ocasiones de plata. Señalaremos que doña Josefa Buenaño Carrasquilla llevaba en su dote entre otras imágenes un Santo Cristo con su dosel, que solía ser adamascado, y una imagen sin identificar» vestida» entre otras. De igual modo aportaba un gran número de láminas de diversas advocaciones religiosas.

\section{¿Cómo evolucionan los objetos religiosos?}

El análisis de la evolución que tuvieron los objetos de culto nos puede aproximar al cambio de mentalidad, de gusto estético y de las prácticas y costumbres religiosas que se debieron producir en el transcurso del XVII al XVIII.

Como ya apuntamos anteriormente la primera idea que podemos extraer es que se produce una disminución de la presencia del total de todos los objetos religiosos, tanto los de uso personal como los del devocionario doméstico, que incluían las mujeres en sus ajuares. En el año 1700 hayamos estos artículos en el $92 \%$ de las dotes mientras en el año 1800 se reduce este porcentaje hasta el 75\%, pero además de disminuir este porcentaje también se reduce el número de artículos pasando de los doscientos sesenta y tres objetos a doscientos treinta y tres. ¿Cuál fue la causa este descenso? A la luz de los datos se constata que este tipo de objetos, y más concretamente a los destinados al hogar, disminuyen en número lo que no es sinónimo de que la religiosidad popular descienda. Nos inclinamos a pensar que es más un cambio de gusto estético que un cambio de mentalidad porque si nos remitimos a esto muchos de estos elementos de devoción han permanecido casi de manera inalterable en los hogares hasta la actualidad.

Apoyamos esta hipótesis por los datos obtenidos en otras parcelas de nuestra investigación general, donde de igual forma otros objetos de adorno destinados al hogar desaparecen, disminuyen y son reemplazados por otros, por el contrario se ha comprobado que los artículos de uso más personal y que se mostraban en público aumentan. Las razones pueden ser variadas desde que la ciudad se urbaniza, lo que facilita que la mujer tienda a salir más fuera del espacio doméstico, hasta la proliferación de las cofradías del Santo Rosario que congregaban a los fieles al rezo en común. Así se puede vislumbrar que la mujer ya no reza tanto en el espacio privado de su casa, sale al rezo del Rosario que se realiza en

${ }^{22}$ Montoro Cabrera, Ma': C. 2003. «El grabado como plasmación de la religiosidad popular» en C. Álvarez Santaló, Ma J. Buxó Rey, S. Rodríguez Becerra (Coords.), La religiosidad popular. Vida y muerte: la imaginación religiosa, V.II: 195. Barcelona: Anthropos Editorial

Hispania Sacra, LXVI

134, julio-diciembre 2014, 575-600, ISSN: 0018-215X, doi: 10.3989/hs.2014.062 
espacios públicos como pueden ser las iglesias o los altares que se encontraban en las diferentes calles, y del que solo queda una muestra en la calle Candelaria esquina con calle Lineros de nuestra ciudad, o las ya mencionadas cofradías que en el caso de Córdoba se encontraban extendidas por gran número de las parroquias existentes en la época ${ }^{23}$ La mujer se sociabiliza más, sale del entorno doméstico y para ello la mujer necesita más objetos de uso personal. Se ha comprobado que casi todas las jóvenes dotadas llevaban un rosario como mínimo independientemente de la cuantía económica de su dote. Ejemplo de ello lo apreciamos en el rosario de madera de cojuelo engarzado valorado en quince reales de vellón que llevaba María de Góngora cuya dote era de tres mil cuatrocientos treinta y siete reales de vellón. ${ }^{24}$

El valor económico de estos objetos igualmente se reduce, en 1700 su valor total es diez mil trescientos ochenta y siete reales de vellón y representa el 3,86\% en el conjunto de las dotes, en el año 1800 su valor total es nueve ciento ochenta y un reales de vellón y representa solo el $1,87 \%$. Resumiendo se produce una triple reducción: de presencia en las listad de bienes, del número de objetos y del valor de los mismos.

$\mathrm{Al}$ diferenciar los objetos religiosos entre los de uso personal y los destinados al espacio doméstico observamos una cierta transformación en la mentalidad que puede ser tanto por la modificación de las costumbres religiosas como por un cambio en los gustos sociales y estéticos.

Tabla II

Evolución de los objetos religiosos (siglos XVII-XVIII)

\begin{tabular}{|l|c|c|c|c|}
\hline \multicolumn{1}{|c|}{ Años } & \multicolumn{2}{c|}{1700} & \multicolumn{2}{c|}{$\mathbf{1 8 0 0}$} \\
\hline \multicolumn{1}{|c|}{ OBJETOS } & CANTIDADES & $\%$ & CANTIDADES & $\%$ \\
\hline PERSONALES & 104 & 39,54 & 217 & 93,13 \\
\hline DOMÉSTICOS & 159 & 60,46 & 16 & 6,87 \\
\hline TOTAL & 263 & 100,00 & 233 & 100,00 \\
\hline
\end{tabular}

Fuente: Elaboración propia

${ }^{23}$ Valero Moreno, M. 2003 «Religiosidad popular en Córdoba en el siglo XVII, cofradías del Santo Rosario» en C. Álvarez Santaló, Ma J. Buxó Rey, S. Rodríguez Becerra (Coords.), La religiosidad popular. Hermandades, romerías y santuarios, V.III: 486. Barcelona: Anthropos Editorial

${ }^{24}$ AHPCO.P.N., 2,Sig. 1.653p, (1700), f.50r 
La tabla II confirma lo expuesto anteriormente, pues se aprecia que en el año 1700 la religiosidad tiene una fuerte presencia en el espacio doméstico, al manifestarse fundamentalmente a través de ciento cincuenta y nueve elementos entre lienzos e imágenes. Esto puede venir motivado porque las familias tendían a vivir más hacia el interior de las casas. La ciudad no estaba preparada para la vida exterior y la casa era el escaparate social y económico del estatus de los habitantes de la casa. Esto propiciaba que los hogares y sus contenidos tuvieran una importancia primordial frente a la visión que los demás tenían de los que vivían en ellas; sin embargo, en el año 1800 los objetos para colocar en las casas descienden a tan solo dieciséis artículos, siendo los objetos personales, cruces y rosarios primordialmente, los que indican la religiosidad de sus propietarios. Hay recordar que en este siglo se inicia la urbanización de las ciudades con la creación de paseos y avenidas que invitan al paseo de sus habitantes. Las mujeres tienen como salida principal de su casa el ir a los rezos del rosario o a la misa diaria o dominical, lo que podría explicar el aumento tan desmesurado de objetos personales religiosos como cruces y rosarios.

La causa de estos cambios pudieron estar motivados por los factores anteriormente apuntados, pero que se produjo un cambio de mentalidad y de gusto estético queda demostrado con los datos numéricos de la tabla de forma irrefutable

\section{¿Quiénes poseen los objetos religiosos del culto privado?}

Pocas son las referencias que nos aportan las cartas de dote y arras sobre las mujeres de esta época y en raras ocasiones aparecen todas juntas en los documentos. No obstante, cuatro criterios cercanos a lo social nos permiten conocer la sociología de los propietarios de los objetos religiosos en los hogares cordobeses del Antiguo Régimen. Cuando constan, son los siguientes:

1) Tratamiento de la incorporación del «doña» $\mathrm{o}$ «no doña», como criterio de cierto nivel social o status.

2) Collación o barrio de la ciudad en la que se inscribe la dotada.

3) La rúbrica del documento que ayuda a calibrar el nivel cultural de la mujer.

4) Importe de la dote que muestra claramente cuál es su posición económica.

Para una mejor comprensión del texto precisaremos que para el análisis de la información económica que aportan los documentos pertenecientes a estas mujeres hemos establecido una escala de las dotes en función de su cuantía económica. Aclaremos que estos niveles ordenados van de cero a nueve mil reales de vellón el primer tramo, de nueve mil un reales de vellón a diecinueve mil reales de vellón el segundo y de esta cantidad en adelante el tercero. A través, 
pues, de los anteriores ítems nos aproximaremos a las mujeres que llevaban al matrimonio los objetos de culto privado.

Observando la globalidad de los datos y siguiendo el orden anteriormente establecido se ha podido comprobar que en 1700 de las cuarenta y nueve mujeres que tienen carta de dote veintiocho llevan el tratamiento de doña y veintiuna se identifica solo por su nombre de pila y apellidos. En cambio en 1800, las mujeres, o más concretamente sus futuros esposos, realizan documentos más elaborados y por lo tanto nos aportan más información.

\section{Gráfico I \\ Distribución de las mujeres en grupos en función de su tratamiento}

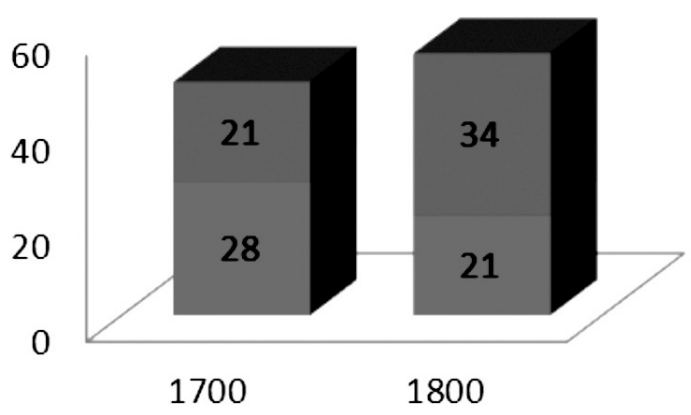

- Tratamiento de doña $\quad$ Sin tratamiento

Fuente: Elaboración propia.

Recordemos que son cincuenta y cuatro las mujeres que realizan inventario ese año. Aún así se ha verificado que los datos se invierten. Se ha comprobado que veintiuna tiene el tratamiento de doña y treinta y siete no. Es significativo el número de mujeres que realizan contratos y que no gozan de tratamiento social, el cual aumenta de manera considerable lo que podría indicar que las mujeres con menor reconocimiento social se incorporan a los modos de los estratos más altos como se muestra en el gráfico I. Este aumento podría significar dos cuestiones: que el menor reconocimiento social no significa que la mujer, más correctamente su familia, no tuviera un poder económico medioalto. La segunda cuestión es la forma de pirámide de la sociedad del Antiguo Régimen donde la inmensa mayoría de la población pertenecía al estado llano, vecinos sin tratamiento ni reconocimiento social independientemente de su nivel económico. 
Antes de reflexionar sobre la mujer por su lugar de procedencia debemos precisar que la ciudad de Córdoba estuvo dividida por una muralla medieval que la separaba en dos partes; la zona alta o Villa donde se situaban los barrios más poblados y de más alto poder social y económico, como era la collación de la Catedral donde se sitúa la residencia de la señora Buenaño y Carrasquilla citada con anterioridad en este trabajo, y la Axerquía donde se concentraba todo tipo de población desde una cierta elite social y económica, como la familia de la dotada doña $\mathrm{M}^{\mathrm{a}}$ Belén Río y Esteban que posee una dote valorada en cuarenta y tres mil seiscientos cincuenta reales de vellón, ${ }^{25}$ hasta la población dedicada a labores artesanales, comerciales y los asalariados ${ }^{26}$ como es el caso del maestro albañil Juan de Talavera del barrio de S. Andrés que se casa con doña Juana $\mathrm{M}^{\mathrm{a}}$ González cuya dote es de tres mil ochocientos noventa y siete. ${ }^{27}$ Se coteja que en 1700 en solo diecisiete casos se anota el barrio al que pertenecen estas mujeres, siendo la mayoría de los barrios de la zona de la Axerquía, con diez casos, frente a los siete de la Villa. Por su parte en 1800 aumenta considerablemente este dato. Se conocen los barrios en los que vivían cuarenta y tres mujeres, quince eran de la villa y veintisiete de la Axerquía. En este punto coinciden las proporciones de los barrios de origen de las mujeres de los años explicados, las de la zona de la Axerquía siguen siendo más numerosas que las de la parte más noble de la ciudad, probablemente como reflejo de una mayor población o quizás de un más acelerado e intenso movimiento de ascenso y promoción social, precisamente por parte de barrios populosos y populares, manifestando el filtro social que es la misma documentación notarial.

La firma de los documentos nos indica el nivel cultural de las personas que aparecen en los mismos. Cuando la mujer, el hombre o ambos no saben escribir se indica literalmente en el documento «no firman porque no saben». La persona que sabe escribir su nombre y apellidos aunque tenga mala letra lo hace, como en el caso de doña Josefa Castro, vecina de la collación de S. Miguel que firma junto a su novio con muy mala escritura la carta de dote y arras otorgada por éste. ${ }^{28}$ Así se confirma que en 1700 las mujeres que dejan su rúbrica en los documentos son tan solo doce, EL 24,5\% de las contabilizadas. En 1800 veintitrés féminas saben firmar los documentos, EL 41,8\% de las cincuenta y cinco contabilizadas lo que supone un considerable aumento. La representación visual la mostramos en la gráfica siguiente.

\footnotetext{
${ }^{25}$ AHPCO.P.N., 2, Sig. 16.432p, (1800), f.163r.

${ }^{26}$ Aranda Doncel, J. 1984, Historia de Córdoba. La época moderna (1517-1808): 20-57 Córdoba: Publicaciones del Monte de Piedad y Caja de Ahorros de Córdoba.

${ }^{27}$ AHPCO.P.N., 2, Sig, 1653p, (1700), f.154r.

${ }^{28}$ AHPCO.P.N., 3, Sig, 16. 212p,(1700), f.389r.
}

Hispania Sacra, LXVI

134, julio-diciembre 2014, 575-600, ISSN: 0018-215X, doi: 10.3989/hs.2014.062 


\section{Gráfico II \\ Distribución de las mujeres en grupos en función de si firman sus documentos}

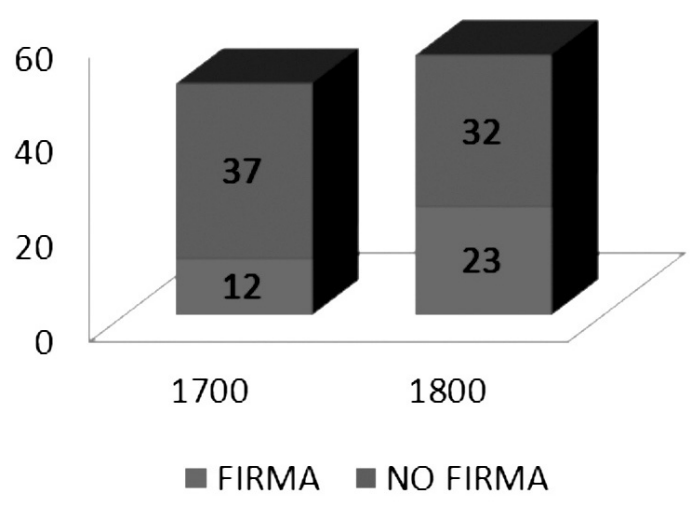

Fuente: Elaboración propia.

Según el gráfico II, tras el paso de un siglo, se produce un aumento notable de documentos firmados, lo que podría indicar una mejora del nivel cultural de las mujeres de la ciudad a la vez que una difusión más amplia de la realización de este tipo de documentos. También nos muestra claramente que las mujeres con menor nivel cultural pertenecen a la gran mayoría de la población que se encuadra en el sector más pobre del tercer estado.

Como último punto consideraremos a las mujeres por la clasificación en tramos económicos de sus dotes. En 1700 se ha precisado que treinta y cinco mujeres pertenecían al nivel económico más bajo, diez al medio y cuatro al más elevado. Por la importancia del valor de sus bienes y a modo de ejemplo nos fijaremos en dos de la mujeres más acaudaladas de este año que son doña Antonia Rafaela del Rosal y Morales, de la collación de san Eulogio y san Nicolás de la Axerquía, con una dote de cincuenta y siete mil doscientos reales de vellón y doña María Bernarda de Mesa y Fustero convecina del barrio de Santa Marina con unos bienes valorados en diecinueve mil doscientos siete reales de vellón. ${ }^{29}$

$\mathrm{Al}$ estudiar las cuantías económicas de las mujeres de 1800 se ha observado que cuarenta están en el nivel más bajo, siete en el medio y ocho son las que tienen una dote superior a diecinueve mil reales. $\mathrm{Al}$ igual que anteriormente destacamos el caso más significativo en ese año el de María del Tránsito Castaño dueña de la dote de más valor con setenta y ocho mil novecientos cincuenta y cinco reales de

${ }^{29}$ AHPCO.P.N., 30, Sig. 10.583p, (1700), f.897r. AHPCO.P.N.2, Sig.1 .653p, (1700), f.267r. 


\section{Gráfico III \\ Distribución de las mujeres en grupos en función del importe de su dote}

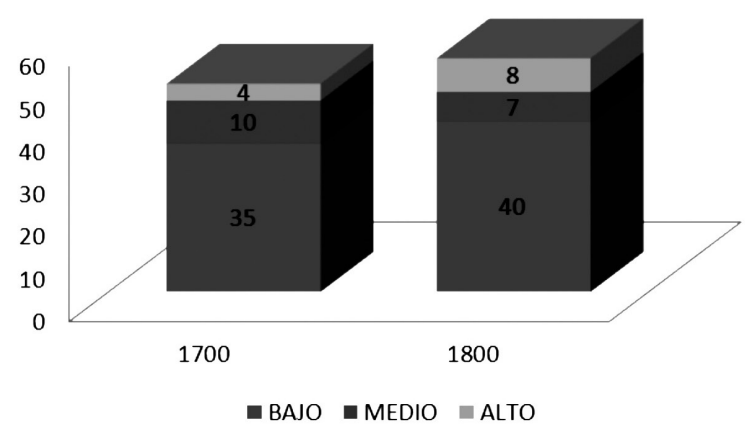

vellón..$^{30}$ Esta viuda tiene como particularidad que sabe firmar pero no tiene un tratamiento social que la distinga. Presumimos que el origen de esta abundante cantidad de dinero está en la herencia que debió de recibir de su anterior marido.

Examinando el anterior gráfico, se comprueba que los extremos económicos, alto y bajo, crecen a lo largo del tiempo estudiado, doblándose en el caso del tramo más elevado. Las capas medias económicas, que no clase media, disminuyen y crece el tramo de dotes más bajas, todo lo que parece indicar que se produce una fractura y un distanciamiento entre los más acaudalados y los más humildes de la sociedad cordobesa. Entre 1700 y 1800 se distingue una evolución positiva en el tramo económico más alto que dobla la cifra a lo largo del tiempo se pasa de cuatro casos registrados en 1700 a ocho dotes en 1800. Igual circunstancia ocurre en las mujeres con bienes de menor valor que también sube situándose cuatro punto por encima del registro del año anterior estudiado. ¿Pero qué ocurre con el grupo de mujeres cuyo ajuar era de un valor medio? Sucede algo muy interesante, que la representación de los bienes de éstas desciende casi paralelamente a lo que suben las del gradiente económico de más alto y de menor poder adquisitivo. ¿Cómo se podría interpretar esta situación? Creemos que de dos maneras contrapuestas pero posibles: La primera interpretación podría ser que las mujeres del tramo económico medio se incorporan al grupo de mujeres con mayor poder adquisitivo y de ahí el aumento de las mujeres más acaudaladas. La segunda, que posiblemente se extendiera la práctica de

\footnotetext{
${ }^{30}$ AHPCO.P.N., 2, Sig. 16.432p,(1800), f.116r.
} 
realizar cartas de dotes y arras entres las mujeres de unos recursos económicos más limitados lo que justifica su aumento. Una tercera posibilidad es que parte de las féminas del tramo económico medio cayera en la precariedad económica incrementando el tramo más bajo y de aquí la subida de los cuatro puntos ya mencionados.

Creemos conveniente recordar que este trabajo está realizado con un número determinado de datos que no recoge a todas las mujeres que se casaban y vivían en Córdoba. Por lo tanto debemos precisar dos cuestiones con respecto a estos contratos: primera que no todas las mujeres que se casaban en Córdoba en los siglos XVII y XVIII realizaban este documento por el coste económico que ello suponía, segunda que solo un número determinado de legajos han sido analizados en este trabajo. Consecuentemente estos testimonios son solo una aproximación y los gráficos su representación visual y no la vida cotidiana de estas mujeres.

Teniendo esto en cuenta ¿qué ideas iniciales se pueden extraer sobre las mujeres que tienen objetos de fe en sus cartas de dote y arras del periodo temporal analizado? En términos generales existe la constante de que la mayor parte de estas féminas no disfrutaba de una buena posición social y que su situación económica no era muy holgada, ya que la generalidad pertenecía al tramo de riqueza más bajo de la sociedad cordobesa. Como se ha manifestado anteriormente, esto no quiere decir que estas mujeres no llevaran objetos de culto, se ha comprobado el hecho contrario, las novias de menos poder económico poseían más artículos de devoción aunque éstos fueran de un escaso valor. Muestra de esto la vemos en la dote de María Fernández cuya cuantía es de tan solo mil sesenta y dos reales de vellón sin embargo posee dos cruces, un rosario y una lámina, todo valorado en treinta y dos reales de vellón. La religiosidad en este caso poco tiene que ver con el poder adquisitivo de la mujer. ${ }^{31}$

Se ha comprobado a lo largo del periodo estudiado que generalmente las contrayentes acaudaladas no disponían de demasiados artículos de devoción tanto personales como para el nuevo hogar, pero sí que muchos de los elementos de piedad más valiosos estaban entre sus ajuares. Este es el caso de doña $\mathbf{M}^{\mathrm{a}}$ del Tránsito Castaño que tiene una lámina de Ntra. Sra. del Rosario valorada en quinientos reales de vellón incluida en una dote de de setenta y ocho mil novecientos cincuenta y cinco reales de vellón.

En otro orden se comprueba que las novias de más alto nivel económico son las que poseen un trato distinguido y son las que saben firmar sus documentos de lo que deducimos que saben leer y escribir.

${ }^{31}$ AHPCO.P.N., 2, Sig. 16.432p,(1800), f.116r 
Entre unas, las más pudientes, y las otras, más humildes, existe una finísima capa de mujeres que van adquiriendo un cierto reconocimiento social, una propensión a firmar sus dotes y un ascenso de su nivel económico de lo que parece ser un sector intermedio, que no clase media, emergente de la sociedad cordobesa de la época, y que podría ser, otra vez, ese signo de ascenso y promoción social que traduce el acceso al notario.

Tras la exposición que nos acerca a estas mujeres en función de sus datos más personales añadiremos la información disponible sobre sus bienes de carácter religioso. En primer lugar y como ya se ha apuntado en alguno de los epígrafes anteriores todas las mujeres sin excepción llevaban entre sus bienes por lo menos un objeto de culto religioso, tanto para uso privado como para colocarlo en la casa. Se ha comprobado que el número y el valor de los objetos de culto que una joven conservaba entre sus posesiones nada tenía que ver con su estatus económico, social o cultural.

Según se ve en el gráfico $\mathrm{V}$ se ha confirmado que el tramo de menor poder adquisitivo comparativamente hablando es el que más recursos emplea en 1700. En este caso el tramo económico bajo emplea un $23,60 \%$ del total de su inversión en estos bienes frente al 21,42\% del tramo medio o el 8,06\% del más rico. Ejemplo de ello es doña Josefa Román de Gárate cuya dote es de solo cinco mil quinientos reales de vellón, el tramo más bajo de los establecidos, cuyos objetos

\section{Gráfico IV \\ Porcentaje de gasto en objetos religiosos en función del importe de la dote 1700}

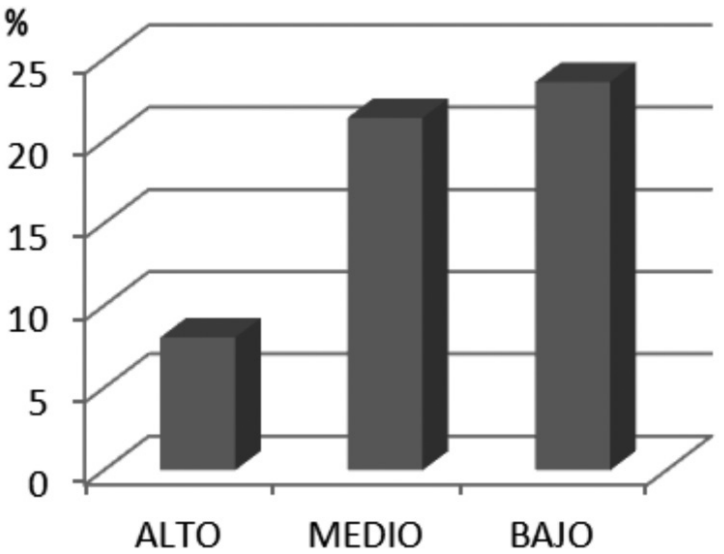

Fuente: Elaboración propia.

Hispania Sacra, LXVI

134, julio-diciembre 2014, 575-600, ISSN: 0018-215X, doi: 10.3989/hs.2014.062 
de culto representan el 10,2\% del valor de su dote de aquí la importancia que esta mujer daba a estos artículos.

En 1800 cambia esta situación cambia de forma radical. Según los datos son las mujeres de más alto poder económico las que más dinero empleaban en objetos religiosos un $32,14 \%$. Las mujeres de tramo económico medio y el tramo bajo descienden su inversión en estos objetos de forma considerable. El tramo medio es el que menos de los tres niveles emplea en estos artículos un $6,17 \%$ del total de su dote. El tramo bajo gasta $8,61 \%$. de su dote en objetos religiosos, lo que supone más de un $2 \%$ en relación al tramo medio. Aún no disponemos de la información necesaria que nos permita conocer las causas de este cambio aunque se puede apuntar por los ítems que en los puntos anteriormente hemos analizados que el gusto por el lujo exterior hace que los más acaudalados emplearan grandes cantidades en prendas religiosas suntuosas que sus mujeres pudieran lucir cuando asistieran a eventos tanto religiosos como mundanos.

\section{Gráfico V}

Porcentaje de gasto en objetos religiosos en función del importe de la dote Año 1800

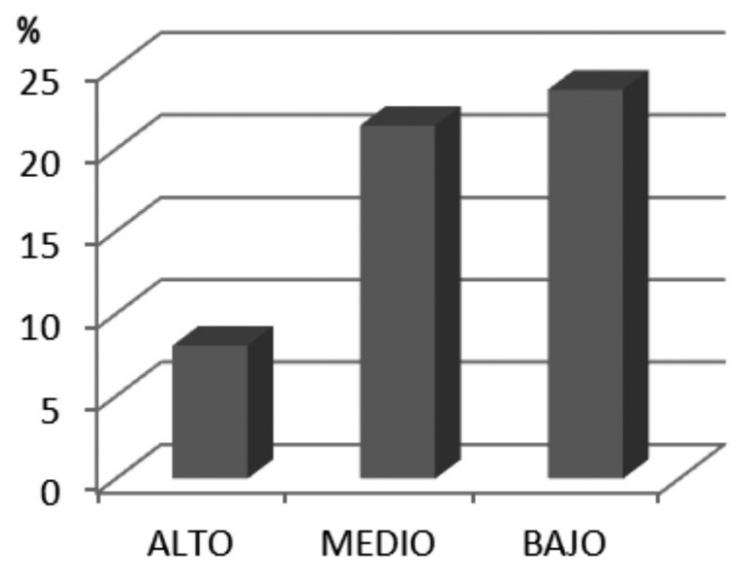

Fuente: Elaboración propia.

Las conclusiones que podemos extraer tras la reflexión efectuada son:

- La mayor parte de las mujeres con mayor poder adquisitivo aquí referidas son las que menos piezas religiosas tienen en propiedad y con un valor insignificante en relación a la cuantía de sus dotes. Ejemplo de ello lo hallamos en 1700 en la pequeña pila de plata y los dos rosarios que importan 
ciento cincuenta y cuatro reales de vellón que proceden de la dote de cincuenta y siete mil doscientos reales de doña Antonia Rafaela del Rosal y Morales lo que le supone solo el 0,26\% del valor total de sus posesiones. En 1800 aparecen casos similares, sirva de muestra el de doña Pilar Muñoz de Velazco y Carrasquilla que solo lleva un rosario con una cruz valorado en ciento veinte reales de vellón frente al total de unos bienes que alcanzan los cincuenta y cuatro mil ciento noventa y siete reales de vellón, lo que significa el $0,22 \%$ del total del valor de la dote. Por lo tanto, se puede apuntar que generalmente aquellas mujeres cuya dote es mayor no siempre llevaban mayor número de objetos aunque posiblemente los más caros, ¿sus caudales invertidos en otros bienes, un posible cambio en los gustos, que va sustituyendo lo religioso por otro tipo de adquisiciones? El nivel de la investigación solo permite las hipótesis, pero ahí quedan.

- Asimismo parece claro que las mujeres que gozaban de menos recursos económicos y una extracción social más baja invierten proporcionalmente más dinero en objetos de culto religioso tanto para su uso personal como para instalar en sus casas, lo que demuestra la importancia que tenía la religiosidad popular en estos años, y tal vez también ese impulso a descollar entre la población que se acerca a la documentación notarial.

- Todas las mujeres, independientemente de su estrato social o de su poder económico, llevaban siempre algún artículo religioso ya fuera para el culto personal o destinado a ser exhibido en algún espacio de la casa. Todo confirma la afirmación inicial de este trabajo la gran impronta que la religión en las vidas de estas personas.

\section{LA EXCEPCIONALIDAD EN LA POSESIÓN DE OBJETOS RELIGIOSOS}

Con anterioridad hemos planteado la regularidad, en cuanto a posesión generalizada, de los objetos religiosos dentro del espacio domestico y en la vida cotidiana, en el análisis global que los ha examinado desde las seis perspectivas posibles. Cierra esta aportación el apartado que señala los casos más singulares en un espigueo que solo pretende ser ejemplo de esa excepcionalidad.

Independientemente del valor de la pieza y de la riqueza que tuviera su dueña encontramos que existen elementos religiosos muy interesantes destinados al uso personal y para el hogar bien por su naturaleza o por la cantidad que de ellos que se presenta.

De este tipo singular destinados al culto privado serían, en primer lugar, un relicario propiedad de doña María San Marcos Navarrete, vecina del barrio de la Magdalena, este relicario era de oro y en su interior figuraba la firma de 
santa Teresa de Ávila. ${ }^{32}$ El valor de este relicario era relativamente alto, ciento cincuenta reales de vellón, pero si lo comparamos con el total del valor de sus bienes, diecisiete mil noventa y dos reales de vellón, no es una cantidad muy exagerada. La singularidad de la pieza reside en el contenido del relicario de esta joven soltera, la firma de la Santa de Ávila. No tenemos datos que nos indiquen la procedencia del documento, si la firma era un original o procedía de un documento impreso. Tampoco sabemos si el relicario había sido un regalo o una herencia por parte de algún familiar, por lo tanto solo se puede reseñar la excepcionalidad del objeto por lo que contenía dentro de él.

Ya hemos comentado a lo largo de todo el trabajo la importancia de los bienes de doña Josefa Buenaño Carrasquilla. Como hemos visto en apartados anteriores, esta mujer lleva un gran número de objetos de carácter religioso tanto para su uso personal como para disponerlos en el hogar. La posible explicación de que esta mujer tuviera todos estos objetos religiosos podía venir motivado por sus circunstancias personales: primero porque su padre era don Juan Ruiz de Buenaño, familiar de Santo Oficio, lo que puede explicar su mayor religiosidad o su predilección por el aparato externo de aquí su religiosidad y la gran cantidad de estos artículos. Segundo porque ella era viuda de don Pedro Jurado y ya había tenido casa propia lo que haría que tuviera un mayor número de objetos. Una curiosidad es que su nuevo marido, don Asciclo Jurado de Montemayor, era sobrino de su anterior marido, lo que confirma las relaciones endogámicas de ciertos sectores elitistas o de capas medias altas de la sociedad del Antiguo Régimen.

Respecto a los elementos de carácter religioso que esta mujer llevaba los comentaremos por su singularidad y por la gran cantidad que encontramos. Si iniciamos nuestro estudio por los elementos religiosos de carácter personal propiedad de esta mujer observamos que poseía seis rosarios, cinco de plata y uno de oro, otra forma más de intercesores terrestres en la religiosidad popular. ${ }^{33}$ La singularidad de estos objetos está en el material con el que estaban sus cuentas fabricadas; el cachimbo, azabache y cuentas azules que eran unidas mediante engarces de plata conformaban los rosarios de plata. Del mismo modo se observa que otro de los rosarios con cuentas de coral disponía de engarces de oro. Finalmente indicar que era propietaria de cuatro agnusdéis de plata y que uno de ellos acogía la imagen de la Virgen del Carmen en una de sus caras. Entre otros objetos de culto privado que poseía se contabilizan dos cruces, una de oro y otra de ébano embutida en marfil que, sin embargo, está valorada en solo 4 reales. Por otro lado entre sus objetos de devoción destinados al hogar

\footnotetext{
${ }^{32}$ AHPCO.P.N., 30, Sig. 10.583p, (1700), f.912r

${ }^{33}$ Vovelle, M. 1978. Piété baroque et déchristianisation en Provence au XVIIIe siècle: 183-228 París: Seuil.
} 
se contabilizan trece lienzos de diferentes santos, vírgenes y cristos. De ellos destacamos cuatro lienzos por estar enmarcados con marcos negro y dedicados a santo Tomás, Nuestra Señora de la Encarnación, Nuestra. Señora de las Angustias y por último a Jesús Nazareno. Con respecto a las imágenes de bulto se anotan cuatro; una de Nuestra. Señora y el Niño sin corona, una imagen del Niño Jesús, un Santo Cristo con su dosel adamascado y una imagen sin especificar la advocación aunque señala que va vestida. Todo lo cual parece indicar que doña Josefa además de ser una mujer bastante acaudalada era una mujer muy devota.

Otro elemento original de uso personal documentado, en una mujer ciertamente acaudalada, es un libro de oraciones o salterio, que llevaba entre sus posesiones doña Gertrudis Calatrava Aguilar, doncella de la collación de san Nicolás y san Eulogio de la Axerquía. ${ }^{34}$ No es un hecho común que en los listados de bienes aparezcan relacionados libros, lo cual puede indicar que esta cordobesa supiera leer, pero lo que sí es claro que es sabía escribir porque estampa su firma en su documento de carta de dote lo que confirma que no era una mujer analfabeta. Podemos apuntar de esta joven que el único objeto religioso que lleva tiene un valor muy modesto, cincuenta reales de vellón, si lo comparamos con el valor de su dote que era de veinticuatro mil reales de vellón, lo que indica que pertenece a la capa económica y social más alta del estado llano. Se ha comprobado que en el conjunto total de las cuantías de las dotes su dote está entre las diez de más valor contabilizadas en 1800

Así mismo encontramos mujeres que entre sus bienes contaban con un gran número de objetos religiosos, estos son los casos de $\mathrm{M}^{\mathrm{a}}$ del Tránsito Castaño y doña Francisca de Herrera.

Traemos a este apartado de nuevo a $\mathrm{M}^{\mathrm{a}}$ del Tránsito, vecina del barrio de san Andrés y de estado civil viuda, por la gran cantidad de rosarios que presenta entre sus bienes ${ }^{35}$ Son quince rosarios, doce son de los denominados de Jerusalén, varios de ellos fabricados en plata y un rosario de oro con una gran cruz valorada en dos mil trescientos reales. No es sorprendente que esta mujer tenga prendas de tanto valor porque sus bienes son los de más valor de todo el tiempo estudiado, setenta y ocho mil novecientos cincuenta y cinco reales de vellón, además es una de las pocas mujeres que firman los documentos, lo que apunta a una fémina de cierto nivel económico y cultural aunque no social porque como se ha apreciado no lleva la denominación de doña.

\footnotetext{
${ }^{34}$ AHPCO.P.N., 2,Sig. 16.432p, (1800), f.286r

${ }^{35}$ AHPCO.P.N., 2,Sig. 16.432p, (1800), f.116r
}

Hispania Sacra, LXVI

134, julio-diciembre 2014, 575-600, ISSN: 0018-215X, doi: 10.3989/hs.2014.062 
De igual forma queremos destacar a doña Francisca de Herrera y Luque, ${ }^{36}$ joven soltera, que lleva entre sus bienes ciento treinta y nueva cruces de diferentes clases y materiales. Entre ellas ciento veintiséis cruces pequeñas y seis cruces de Caravaca, es muy significativa una cruz de oro y esmeraldas de color valorada en doscientos diez reales. A todas ellas se pueden añadir seis agnusdéis que estaban realizados con la técnica denominada filigrana. Una particularidad que hay que destacar en esta mujer es el gusto por estos objetos delicados ya que junto a los bienes de culto religioso fabricados de esta forma artesanal, como seis agnusdeis, encontramos otros de estos finos artículos para su adorno personal como sortijas y zarcillos.

De la misma manera poseía entre sus bienes cuatro libros de los cuales tres incluían tapas de filigrana y del cuarto se dice que es un «librito de plata». Según este balance, varias son las hipótesis explicativas: Bien que a esta mujer, doña Francisca, le gustaba coleccionar objetos religiosos, de aquí la gran profusión de cruces, o bien que las hubiera heredado de algún familiar, cosa poco probable porque de ser así constaría por escrito. Otra posibilidad es que tuviera alguna relación con el gremio de los plateros porque entre sus otros bienes encontramos un banco de platería lo que podría indicar que dispusiera de todo este género para comerciar con él y de esta manera aportar un capital al matrimonio. Como está siendo la norma en los anteriores casos comentados doña Francisca de Herrera y Luque poseía un alto poder adquisitivo, pues su dote alcanzaba los veintiún mil cuatrocientos reales de vellón. Esta circunstancia coincide con las otras mujeres de alto poder económico que también sabían escribir, porque sus carta de dote estaban firmadas por ellas.

Por último, citaremos a doña María Ignacia Collado Ramírez, quien entre sus artículos de culto destinados al hogar lleva tres retablos de tamaño grande, otros tres retablos de pequeño formato y una hechura de un Santo Cristo con su dosel. ${ }^{37}$ La singularidad de los objetos viene por los elementos en sí mismos, los retablos, y por la cantidad que de ellos lleva, seis. Nos preguntamos dónde colocaría y el uso que esta mujer daría a estos objetos por ser tan especiales.

Para finalizar como resumen y retrato de la religiosidad femenina analizada a través de sus bienes de devoción y culto privado diremos que de acuerdo con la mentalidad religiosa dominante es bastante comprensible que la mayor parte de los hogares analizados dispusieran de objetos religiosos ya fueran para el culto doméstico o personal de sus habitantes. Las mujeres que preparaban el ajuar para su nuevo hogar en los siglos XVII y XVIII siempre incluían algunos objetos de

\footnotetext{
${ }^{36}$ AHPCO.P.N., 34, Sig.2.185p, (1800), s.f.

${ }^{37}$ AHPCO.P.N., 5, Sig. 15.912p, (1700), f.234.
} 
culto privado tanto para su uso personal como para colocarlos en algún espacio de la casa.

Con respecto al número de objetos que llevaban estas jóvenes, la norma era que llevaran entre uno y tres objetos que generalmente eran rosarios de plata para el rezo diario, y lienzos con temática cristológica y mariana para la vivienda. Todo esto independientemente de la posición económica y social que tuvieran las poseedoras.

Así mismo se ha comprobado que a lo largo del todo el periodo estudiado los objetos de culto y devoción disminuyen. No es que el individuo renunciara a su religiosidad, más bien se puede intuir que se empezaba a vivir la religiosidad de una manera distinta. En definitiva, la religiosidad privada reflejada en el número de los objetos tanto personales como los destinados al espacio de la casa descendió, aunque no desapareció, tal y como parecen apuntar otros estudios sobre comportamientos religiosos para la misma época. ${ }^{38}$

En definitiva esta forma de religiosidad se ha seguido trasmitiendo a lo largo del tiempo y muchos de estos objetos se han seguido utilizando a lo largo de los siglos, bien es cierto que en algunos casos han perdido su significado originario como apuntaba Zamora Acosta para adquirir un significado supersticioso o se han transformado en objetos de adorno. Pero lo interesante es que han perdurado como bienes materiales que reflejan el sentido intangible de la religión

\section{BIBLIOGRAFÍA}

Abellán Pérez, J. 2009. El ajuar en las viviendas murcianas a finales de la Edad Media, Murcia, Real Academia de Alfonso X, el Sabio.

Aguilar Piñar, F. 2003 «Predicación y mentalidad popular en la Andalucía del siglo XVIII» en C. Álvarez Santaló, M ${ }^{\mathrm{a}}$ J. Buxó Rey, S. Rodríguez Becerra (Coords.), $L a$ religiosidad popular. Vida y muerte: la imaginación religiosa, V.II: 57-72 Barcelona: Anthropos Editorial.

Ariès P. y Duby G.1989. (dirs), Historia de la vida privada, 3: Del Renacimiento a la Ilustración, Madrid, Taurus.

\footnotetext{
${ }^{38}$ Aguilar Piñar, F. 2003 «Predicación y mentalidad popular en la Andalucía del siglo XVIII» en C.

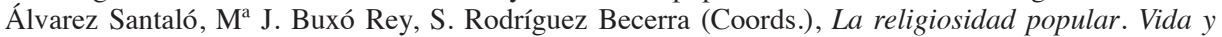
muerte: la imaginación religiosa, V.II: 57-72 Barcelona: Anthropos Editorial.

Franco Rubio, G.A.2009. «La vivienda en el Antiguo Régimen: de espacio habitable a espacio social». Chronica nova: Revista de historia moderna de la Universidad de Granada 35: 63-103.
} 
Bartolomé Bartolomé, J. M. y García Fernández, M. 2012. (dirs), Apariencias contrastadas: contraste de apariencias. Cultura material en el Antiguo Régimen. León, Universidad de León.

Blasco Esquivias, B. 2006. (dir), La casa: evolución del espacio doméstico en España, 1, Madrid, Ediciones El Viso.

Escribano Nieto, $\mathrm{M}^{\mathrm{a}}$ J. 2012 «La religiosidad popular cordobesa: las advocaciones de gloria. Pervivencia y desaparición de estas imágenes y sus lugares de culto» en F. J. Campos y Fernández de Sevilla (Dir.), Advocaciones marianas de gloria: 263-314. San Lorenzo del Escorial, Ediciones Escurialenses: Real Centro Universitario EscorialMaría Cristina.

García Fernández, M.2009. «Entre_cotidianidades: vestidas para trabajar, de visita, para rezar o de paseo festivo», Cuadernos de Historia Moderna, VIII: 119-150.

Gila Medina. 2011. «El Cristo de Burgos o de Cabrilla en la Diócesis de Granada» Contraluz: Revista de la Asociación Cultural Arturo Cerdá y Rico 8: 129-164

Gómez Navarro, M ${ }^{a}$ S.1998. Una elaboración cultural de la experiencia del morir, Córdoba, Universidad de Córdoba.

- (1998-1990). «Acercamiento a la muerte desde la antesala de la muerte misma: las ultimidades», Revista de historia moderna: Anales de la Universidad de Alicante: 21-32.

- 2008. «Un momento ideal para acordarse de los Santos: Cuando la muerte llega: la cláusula testamentaria de la intercesión en la España Moderna» en F.J. Campos y Fernández de Sevilla (Dir.), El culto a los santos: cofradías, devoción, fiestas y arte,:5774.San Lorenzo del Escorial, Ediciones Escurialenses: Real Centro Universitario Escorial-María Cristina.

González Sánchez, C. A. 2012 «Imagen de culto y espiritualidad. Funciones y normas de uso en la vida cotidiana (siglos XVI-XVII) en M. Peña Díaz (Ed.), La vida cotidiana en el mundo hispánico (siglos XVI-XVII), 387-405. Madrid: Abada Editores.

Franco Rubio, G. A.2009. «La vivienda en el Antiguo Régimen: de espacio habitable a espacio social». Chronica nova: Revista de historia moderna de la Universidad de Granada_35: 63-103.

Montoro Cabrera, $M^{\text {a }}$ : C. 2003. «El grabado como plasmación de la religiosidad popular» en C. Álvarez Santaló, M ${ }^{\mathrm{a}} \mathrm{J}$. Buxó Rey, S. Rodríguez Becerra (Coords.), La religiosidad popular. Vida y muerte: la imaginación religiosa, V.II: 190-201. Barcelona: Anthropos Editorial.

Morcillo Portal, M. A. 1997. «Bienes dotales suntuario en la Málaga del siglo XvıII», en $\mathrm{M}^{\mathrm{a}}$.V. López Cordón, M. Carbonell Esteller, M. (edits.), Historia de la mujer e Historia del matrimonio, 173-178.Murcia, Universidad de Murcia.

Peña Díaz, M. 2010. «La vida cotidiana en la época moderna: Disciplina y rechazo.» Historia Social, 66:41-66. 
Pouns Norman, J. G.1992. La vida cotidiana: Historia de la cultura material, Barcelona, Crítica.

Sarti, R. 2002. La vida en familia. Casa, comida y vestido en la Europa Moderna, Barcelona, Crítica.

Thompson, E. P. 1995. Costumbres en común, Barcelona, Crítica.

Valero Moreno, M. 2003 «Religiosidad popular en Córdoba en el siglo XVII, cofradías del Santo Rosario» en C. Álvarez Santaló, Ma J. Buxó Rey, S. Rodríguez Becerra (Coords.), La religiosidad popular. Hermandades, romerías y santuarios, V.III:485506. Barcelona: Anthropos Editorial.

Vovelle, M. 1978. Piété baroque et déchristianisation en Provence au XVIIIe siècle: 183-228 París: Seuil.

Zamora Acosta, E. 2003. «Aproximación a la religiosidad popular en el mundo urbano: el culto a los santos en la ciudad de Sevilla» en C. Álvarez Santaló, Ma J. Buxó Rey, S. Rodríguez Becerra (Coords.), La religiosidad popular. Antropología e historia, V.I: 541. Barcelona: Anthropos Editorial. 